\title{
Gestión de los costes de calidad en los servicios sociales: un reto para las entidades no lucrativas del País Vasco
}

\author{
Javier Corral-Lage
}

Facultad de Ciencias Económicas y Empresariales de Bilbao, Universidad del País Vasco/Euskal Herriko Unibertsitatea (UPV/EHU)

\section{Miren Lorea Maguregui Urionabarrenechea}

Escuela Universitaria de Estudios Empresariales de Bilbao, Universidad del País Vasco/Euskal Herriko Unibertsitatea (UPV/EHU) <lorea.maguregi@ehu.es>

\section{Crisanta Elechiguerra Arrizabalaga}

Escuela Universitaria de Estudios Empresariales de Bilbao, Universidad del País Vasco/Euskal Herriko Unibertsitatea (UPV/EHU)

Euskal Herriko irabazi-asmorik gabeko erakundeek, kalitatearen kudeaketa eta kostuei dagokienean, egiteko garrantzitsu bat daukate: burutzen dituzten jardueren kalitate kostuen neurketa. Beraien kudeaketari ondoen egokitzen den sistema garatu behar dute, arlo ekonomiko/finantzario eta gizartearloaren arteko oreka lortzea lagatzen duten tresnak sortuz eta aplikatuz. Ikerketa hau Euskal Herrian gauzatzen da, irabazi-asmorik gabeko erakundeen kalitate eta kostuetan ardura handia duen erkidego batean. Urriaren 7ko 424/2013 Dekretuaren bidez, Gizarte-zerbitzuetako irabazi-asmorik gabeko erakundeak gizarte-intereseko deklaratzeari buruzkoa, Eusko Jaurlaritzak ondorengo hau zehazten du: zerbitzuak adjudikatu eta kontratua eskaintzerakoan, euskal administrazioek, beraien jardueraren kalitatea eta efikazia frogatu eta lehiakideen kostu berberak eskaintzen dituzten erakundeak aukeratu beharko dituztela lehendabizi.

\section{GAKO-HITZAK:}

Kudeaketa, kostuak, kalitatea, irabazi-asmo gabeko erakundeak, gizarte-zerbitzuak.,
Las entidades no lucrativas del País Vasco, en lo que a la gestión de la calidad y sus costes se refiere, tienen pendiente un aspecto primordial: la medición de los costes de calidad de sus actividades. Precisan desarrollar el sistema que mejor se adecue a su gestión, creando y aplicando herramientas que permitan lograr el equilibrio entre la dimensión económico-financiera y la social. La presente investigación se centra en el País Vasco, comunidad con una gran preocupación por la calidad y sus costes. Mediante el Decreto 424/2013, de 7 de octubre, sobre la Declaración de Interés Social de las Entidades sin Ánimo de Lucro de Servicios Sociales, el Gobierno Vasco establece que las administraciones vascas, a la hora de adjudicar servicios y ofrecer contratos, tendrán que elegir primero a aquellas que acrediten calidad y eficacia en el ámbito de sus actuaciones, y además ofrezcan los mismos costes que sus competidores.

\section{Palabras Clave:}

Gestión, costes, calidad, entidades no lucrativas, servicios sociales. 


\section{Introducción}

Las entidades no lucrativas juegan un papel vital en la sociedad (Unerman y O’Dwyer, 2010), pues ofrecen una gran pluralidad de servicios, como salud, cultura y ocio, servicios sociales, educación e investigación, o servicios laborales. Han nacido con objetivos filantrópicos y de caridad, desarrollan servicios de carácter social y humano, e históricamente han sido promovidas y gestionadas, sobre todo, por personas voluntarias, por lo que durante muchos años no han tenido la obligación de entregar su información económico-financiera al Estado. Así, un problema común a las organizaciones de este sector es la carencia o insuficiencia de rendición de sus cuentas (Rovira, Jerez y Johanisova, 2012: 164). Además, pueden estar constituidas formalmente bajo diferentes formas jurídicas -asociaciones, fundaciones, federaciones, colegios profesionales, grupos, plataformas, reuniones, confederaciones-, lo cual hace que la cuantificación total del sector resulte difícil, si no imposible, y que se asemeje a un mosaico cada vez más diversificado (Ruiz Olabuénaga, 2006: 249). Actualmente, detrás de la denominación de organizaciones no lucrativas existe gran variedad de actividades, finalidades y aspectos socioculturales y políticos, por lo que no resulta fácil encontrar una clasificación única, ni estructurar las investigaciones en grandes líneas temáticas (García Delgado, 2009: 97-98). Se trata, por lo tanto, de un campo muy dinámico y plural, de límites desdibujados y difíciles de concretar (Socías et al., 2013: 34).

Resulta complicado planificar, medir y controlar los objetivos de las entidades no lucrativas (Asociación Española de Contabilidad y Administración de Empresas, 2002). En estas organizaciones, dirigidas por valores y con un importante componente voluntario, es necesario alcanzar un amplio acuerdo y lograr una visión compartida de lo que se quiere hacer (Mataix, 2001). Es decir, deben definir con exactitud su misión y objetivos, de manera que sean asumidos por todos los miembros de la organización. De no ser así, el desarrollo de indicadores o medidas de la consecución de esos objetivos en las distintas áreas de la organización resultará imposible, con lo que la medición del impacto de sus actuaciones será muy difícil.

Los sistemas informales de comunicación suministran una imagen general del estado en que se encuentra la organización, pero no permiten realizar un análisis en profundidad, por lo que problemas aparentes pueden acabar absorbiendo muchos recursos, mientras que problemas de mayor relevancia quedan desatendidos. La carencia de información racional promueve actuaciones precipitadas basadas en la intuición (Senovilla, 2013). Para anticiparse a posibles problemas, el control de costes resulta imprescindible (Vassallo, 2012).

En el caso de las entidades no lucrativas, es necesario implantar una gestión específica de recogida y tratamiento de los datos con el fin de estimar el coste económico de cada actividad, programa, producto o servicio. Los sistemas de cálculo de costes son la base de la información para la gestión de las organizaciones (Ripoll, 2012) y estarán en función de la estructura organizacional y de los objetivos que se quieran obtener con el cálculo de dichos costes. La necesidad de reducir costes y de invertir en innovación son dos de las claves del sector (Fundación PricewaterhouseCoopers, 2013, 2014).

Como sabemos, las entidades no lucrativas están obligadas a perseguir la misión para las que han sido creadas y han de vigilar la correcta puesta en marcha y posterior desarrollo de los programas, proyectos y actividades que han de realizan a tal fin. Para cumplir la exigencia, tanto interna como externa, de una gestión de calidad y transparente que responda a sus necesidades, precisan conocer y aplicar herramientas de gestión de la calidad que sean capaces de medir su efectividad y de mejorar la eficiencia y eficacia. Es decir, herramientas fundamentales de gestión, planificación, medición y evaluación necesarias para la mejora continua. Por lo tanto, la implementación formalizada de sistemas de gestión de la calidad constituye un verdadero reto para estas organizaciones (Fundación EDE, 2008).

En este sentido, el conocimiento y utilización de las herramientas de la contabilidad de gestión resulta imprescindible para el correcto diseño de un sistema de gestión, puesto que pueden ofrecer información económica relevante, de mayor calidad y cantidad, para la toma de decisiones y el control de la actuación. Las ventajas que presenta la contabilidad de gestión justifican su implantación, puesto que facilita el control y la reducción de costes, así como la mejora de la gestión (Ripoll, 1996: 16).

En el trabajo de la Asociación Española de Contabilidad y Administración de Empresas Estudio sobre la implantación de la contabilidad de gestión en España (1994: 17), se establece que los objetivos más importantes para los profesionales de la contabilidad son, y por este orden, la toma de decisiones, el cálculo de costes y resultados, el control, la información para cuentas anuales y la planificación.

En España no existe normativa contable de costes específica. El Instituto de Contabilidad y Auditoría de Cuentas (1998: 58) recomienda a las entidades no lucrativas la aplicación de cualquier sistema de contabilidad de costes con el fin de enriquecer la información financiera-contable que puedan ofrecer, y a su vez, para que puedan obtener información de sus costes y poner en marcha la política de precios y cuotas más adecuadas en sus transacciones económicas.

El tercer sector debe enfrentarse, así, a una dura y profunda reconversión. Una reestructuración casi 'milagrosa': con la fuerza de sus valores propios y de su compromiso con las personas y la sociedad, pero sin recursos específicos para transformarse en las organizaciones del siglo XXI que son imprescindibles actualmente (Vidal, 2013b). Puesto que los 
orígenes del problema de la calidad se encuentran distribuidos por todas las áreas de la organización, se requiere el análisis de la información obtenida en la evaluación de todos los procesos y resultados, con el fin de contrastar el logro de los objetivos, detectar problemas, proponer acciones correctoras y, así, encaminar a las organizaciones hacia la mejora de la calidad. La evaluación de la calidad en las organizaciones no lucrativas puede ofrecer grandes ventajas, puesto que permite introducir medidas de mejora y reducir los costes de los errores. Se debe generar un ahorro basado en el aumento de eficiencia: las estructuras muy pequeñas tienen muchas ineficiencias, que acaban generando unos costes altos de funcionamiento que no se pueden permitir. Colaborar, compartir, repartir, coordinar, fusionar o reutilizar serán verbos que guiarán las actuaciones de las entidades no lucrativas estos años (Vidal, 2013a).

Por todo ello, consideramos interesante investigar la situación actual de las entidades no lucrativas del País Vasco en lo que a la gestión de la calidad y sus costes se refiere.

\section{Objetivo de la investigación}

El objetivo de esta investigación empírica es ofrecer un acercamiento al panorama actual y las tendencias de las entidades no lucrativas privadas del País Vasco en lo referente a la gestión de la calidad y sus costes, a partir de la percepción de las propias organizaciones, recogida mediante una encuesta. Se trata de elementos que contribuyen a mejorar su gestión y, con ello, a lograr que sean más eficaces y eficientes, lo que les permite transmitir una imagen de seriedad y de excelencia del sector no lucrativo. Para alcanzar el fin propuesto, se analizan la caracterización de las entidades, la medición de los costes de calidad, así como el conocimiento y la aplicación de las herramientas de gestión de la calidad y los modelos de costes totales de calidad.

\section{3. Ámbito de la investigación}

Nos hemos centrado en el País Vasco por ser una comunidad autónoma con una gran tradición en entidades no lucrativas y, a la vez, con una enorme preocupación por el sector. Tenemos que recordar que la Ley 12/1994, de 17 de junio, de Fundaciones del País Vasco se adelantó cinco meses a la primera normativa estatal significativa, sobre todo en materia contable, para este tipo de organizaciones. Además, a lo largo de los últimos años y para regular perfectamente esta parte tan importante de los recursos humanos de las entidades no lucrativas, esa preocupación ha llevado a la prórroga del II Plan Vasco de Voluntariado (Gobierno Vasco, 2011).

Asimismo, nuestro interés por la calidad y sus costes en las entidades no lucrativas privadas del País Vasco también es compartido por el Gobierno Vasco, quien mediante el Decreto 424/2013, de 7 de octubre, sobre la Declaración de Interés Social de las Entidades Sin Ánimo de Lucro de Servicios Sociales, establece que las administraciones vascas, a la hora de adjudicar servicios y ofrecer contratos, tendrán que elegir primero a aquellas entidades no lucrativas que, reuniendo las condiciones que se determinen reglamentariamente, acrediten calidad y eficacia en el ámbito de sus actuaciones, y puedan además ofrecer los mismos costes que sus competidores. Como señala el preámbulo de dicha normativa, esta ventaja pretende preservar la identidad propia y diferenciada del tercer sector de acción social de Euskadi.

\section{Enfoque metodológico}

Dadas sus características y objetivos, este trabajo estudia la realidad en su contexto natural, intentando comprender e interpretar los fenómenos de acuerdo con los significados que tienen para las personas implicadas. Se trata, por lo tanto, de una investigación empírica exploratoria, fundamentalmente cualitativa. En este estudio, más que un contraste de hipótesis con técnicas más o menos sofisticadas, se ha pretendido detectar y analizar aspectos relevantes de las entidades no lucrativas privadas del País Vasco relativos a la gestión de la calidad y sus costes.

La dimensión temporal no se considera un aspecto relevante para la investigación y el estudio prioriza el detalle y la profundidad, más que la cantidad, en la adquisición de información. Tiende a mantener la perspectiva de un enfoque abierto que permita construir o completar el conocimiento.

En las ciencias sociales existen diversos métodos para llevar a cabo una investigación empírica. Todas las metodologías tienen ventajas y limitaciones y, $a$ priori, ninguna es mejor que la otra. La elección de un método u otro dependerá, entre otras variables, de las características y la naturaleza de la investigación:
La metodología cualitativa es tan válida como la cuantitativa y su diferencia estriba en la dife- rente utilidad y capacidad heurística que poseen, lo que les hace recomendables en casos y situaciones distintas. El acierto del investigador depende no de la metodología que utiliza sino del acierto en aplicarla en aquellos casos específicos para los que está más adaptada. (Ruiz Olabuénaga, 2012: 17).

Éste es un trabajo eminentemente inductivo, en contraposición al positivismo, sin que eso suponga, en absoluto, una renuncia a esa forma de investigación. Somos conscientes de las críticas que puedan realizarse a un trabajo de carácter cualitativo en contraposición a uno cuantitativo, pero las rigurosas publicaciones científicas de autores como Eisenhardt (1989), Yin (1994), o Miles y Huberman (1994) sobre el proceso de investigación exploratoria, los trabajos que se han realizado con este enfoque, y el aval de autoridades como Kaplan (1983) hace que nos reafirmemos en nuestra decisión. 
Merece la pena destacar el artículo escrito por Martínez Churiaque (2003), en el que comenta el verdadero avance obtenido en el pensamiento contable debido a la investigación empírica, criticando la poca aportación de los trabajos positivistas frente a los fenomenológicos. Como advierte el autor, se están realizando estudios que están fuera de la esfera empírica y no despiertan ningún interés entre los investigadores de este ámbito (ibídem: 1.218).

\section{Estudio empírico}

\subsection{Encuesta}

La técnica utilizada en el estudio empírico, como se ha señalado, es la encuesta (Tabla 1). La información que se obtiene a partir de este instrumento es un elemento esencial en la toma de decisiones, puesto que su posterior análisis e interpretación permite a los responsables de la organización prever y controlar sabiendo. Permite dirigirse a poblaciones extensas y obtener simultáneamente datos de varias personas de una forma estructurada.

\subsection{Objeto}

La falta de datos globales caracteriza al sector no lucrativo, siendo España uno de los países europeos que más atrasado van en este sentido, posiblemente porque se ha empezado a investigar el sector, sobre todo el privado, en los últimos veinte años. Como señala el estudio de la Confederación Empresarial Española de Economía Social (2011) sobre el impacto socioeconómico de las entidades de Economía Social, la cuantificación requiere información específica y actualizada que incluya a las distintas entidades de este campo y que permita trabajar con muestras amplias, por lo que la falta de información estadística adecuada es uno de los elementos que han frenado los análisis de impacto de este sector.

La inexistencia de registros y fuentes oficiales únicas y actualizadas de donde se pueda extraer la información es el principal problema a la hora de saber cuántas son y de conocer su magnitud económica (número de socios, número de voluntarios que trabajan en ellas, ingresos que movilizan, aportación a la economía). En el País Vasco, concretamente, existe el
Registro de Fundaciones del País Vasco y también el de Asociaciones. Además, son varias las corporaciones locales que cuentan con registros propios.

Tampoco podemos olvidar, como señala García Delgado (2009: 109), que los registros tienen carácter histórico, acumulativo, por lo que "las entidades se van dando de alta cuando empiezan a actuar, sin que, de manera sistemática, se las dé de baja en el momento que dejan de hacerlo". Es decir, en los datos procedentes de los registros no existe constancia fehaciente de que las entidades estén activas.

También están, por otro lado, los datos del Directorio Central de Empresas (DIRCE) del Instituto Nacional de Estadística, que, en el apartado de 'Asociaciones y otros tipos', recoge todas aquellas organizaciones con actividad económica, con número de inscripción fiscal y número de inscripción de la Seguridad Social. En él están incluidas asociaciones, fundaciones, cofradías, clubes deportivos, mutuas, mutualidades de previsión social y cajas de ahorro. No obstante, este directorio no contabiliza todas aquellas organizaciones sin actividad económica, pero que pueden estar activas.

Además, como señala Álvarez de Mon (1998: 128), a este desconocimiento contribuye la propia Administración:

Independientemente de la mayor o menor opacidad informativa de las organizaciones, la administración pública tiene que garantizar un nivel mínimo de información y transparencia que permita evaluar y controlar la dimensión y alcance de este sector. Sorprende negativamente la escasa, irrelevante y poco contrastada información que existe. La información que obra en poder el Registro de Asociaciones, del Inventario de Fundaciones tuteladas por el Ministerio de Asuntos Sociales, así como de otros centros informativos no permite, por razón de su propia naturaleza, recoger el dinamismo y evolución económica y social de las organizaciones del sector.

\subsection{Muestra}

La principal fuente para elaborar el censo actualizado de las entidades no lucrativas objeto de nuestro estudio han sido los datos del Eustat-Instituto Vasco de

Tabla 1. Ficha técnica de la encuesta

\begin{tabular}{|l|l|}
\hline Universo & Responsables del área de gestión de entidades no lucrativas privadas del País Vasco \\
\hline Técnica & Encuesta en línea \\
\hline Tamaño de la encuesta & 643 \\
\hline Cuestionarios contestados & 194 \\
\hline Fecha del trabajo de campo & Otoño de 2012 \\
\hline Herramienta de procesamiento de datos & Excel, versión 2007 \\
\hline
\end{tabular}

Fuente: Maguregui (2014). 
Estadística. Según éstos, en el País Vasco son 20.431 las asociaciones registradas, y conforme hemos podido comprobar, a mediados de 2012 son 590 las fundaciones que aparecen en el Registro.

Teniendo en cuenta las entidades no lucrativas objeto de nuestra investigación, y sin olvidar que los tres ejes que delimitan el área de las instituciones privadas sin fines de lucro son su carácter privado, formal y no lucrativo, se han excluido de este directorio las asociaciones políticas, sindicales, organizaciones empresariales, iglesias, confesiones y comunidades religiosas, federaciones deportivas, comunidades de bienes y propietarios, las entidades que se rigen por el contrato de sociedad, cooperativas, mutualidades, cajas de ahorro, empresas de inserción, uniones temporales de empresas y agrupaciones de interés económico.

Además, según hemos podido constatar, hay muchísimas que han desaparecido o permanecen inactivas. Ante la inexistencia de un censo oficial de asociaciones y fundaciones en activo, y tomando como base los datos de la Encuesta CIRIEC-2008, Monzón Campos (2010: 123) señala que, de las asociaciones inscritas y no disueltas, sólo el $48 \%$ desarrollaban alguna activi-

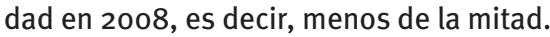

Para la delimitación del universo de nuestro estudio, tarea que ha resultado laboriosa y complicada, basándonos en los datos anteriormente citados, y a falta de información más fidedigna, se ha supuesto que el número de entidades no lucrativas privadas activas del País Vasco sería de unas 6.430. Lamentablemente, como señalan Montserrat Codorniu y Rodríguez Cabrero (1996), mientras no se verifiquen las organizaciones activas, sólo se podrá hablar del número de organizaciones que forman el universo de este estudio como una cifra aproximada.

Se remitieron un total de 643 cuestionarios a entidades no lucrativas privadas activas del País Vasco de las que se disponía su dirección de correo electrónico, y a las que se transmitió la garantía absoluta de confidencialidad, así como que en ningún momento se daría a conocer la identidad de las personas que cumplimentaran el cuestionario. De los remitidos, se obtuvieron 194 debidamente contestados, lo que supone un índice de respuesta del 30,1\%.

Para calcular el error estadístico, utilizamos la siguiente fórmula (Ortega Martínez, 1994: 323):

$$
e=\sqrt{\frac{k^{2} \cdot p \cdot q \cdot(N-n)}{n \cdot(N-1)}}
$$

Donde $e$ es el error, $k$ es el valor para asignar el nivel de confianza, siendo:

- $k=1,96$ para un nivel de confianza del $95 \%$.

- $\quad p$ y $q$ son valores de confianza de los datos, para los cuales, en el peor de los casos, los valores serían $p=q=50$.

- $n$ es el tamaño de la muestra.
- $\quad N$ es el universo.

El error sería de $\pm 6,93 \%$.

\section{Resultados del trabajo de campo}

La información obtenida en el estudio empírico se ha agrupado en varias categorías, que se examinan en los siguientes subapartados.

\subsection{Parámetros descriptivos definitorios de las entidades}

La Tabla 2 sintetiza el perfil de las 194 entidades no lucrativas analizadas.

Tabla 2. Caracterización de las entidades no lucrativas privadas del País Vasco $(N=194)$

\begin{tabular}{|c|c|c|c|}
\hline & \multirow{2}{*}{$\begin{array}{c}n \\
121\end{array}$} & \multirow{2}{*}{$\begin{array}{l}\% \\
62\end{array}$} \\
\hline \multirow{3}{*}{ Forma jurídica } & Asociación & & \\
\hline & Fundación & 62 & 32 \\
\hline & Otra & 11 & 6 \\
\hline \multirow{3}{*}{$\begin{array}{l}\text { Lugar de desarrollo de } \\
\text { la actividad propia }\end{array}$} & Sólo País Vasco & 134 & 69 \\
\hline & $\begin{array}{l}\text { País Vasco y otras } \\
\text { comunidades } \\
\text { autónomas }\end{array}$ & 56 & 29 \\
\hline & $\mathrm{NS} / \mathrm{NC}$ & 4 & 2 \\
\hline \multirow{3}{*}{$\begin{array}{l}\text { Desarrollo de actividad } \\
\text { mercantil }\end{array}$} & Sí & 43 & 22 \\
\hline & No & 147 & 76 \\
\hline & NS/NC & 4 & 2 \\
\hline \multirow{3}{*}{ Antigüedad } & $<5$ años & 10 & 5 \\
\hline & 5-10 años & 19 & 10 \\
\hline & $>10$ años & 165 & 85 \\
\hline \multirow{5}{*}{$\begin{array}{l}\text { Porcentaje de } \\
\text { voluntarios con } \\
\text { respecto a los } \\
\text { trabajadores } \\
\text { empleados durante el } \\
\text { ejercicio }\end{array}$} & $0 \%$ & 45 & 23 \\
\hline & $<10 \%$ & 25 & 13 \\
\hline & $10-20 \%$ & 27 & 14 \\
\hline & $>20 \%$ & 91 & 47 \\
\hline & $\mathrm{NS} / \mathrm{NC}$ & 6 & 3 \\
\hline \multirow{4}{*}{ Presupuesto anual } & $\leq 30.000 €$ & 27 & 14 \\
\hline & $30.001-100.000 €$ & 45 & 23 \\
\hline & $>100.000 €$ & 120 & 62 \\
\hline & $\mathrm{NS} / \mathrm{NC}$ & 2 & 1 \\
\hline
\end{tabular}

NS/NC: no sabe o no contesta. Fuente: Maguregui (2014).

Destacamos que:

- Se trata de un sector con mucha tradición y experiencia. La inmensa mayoría de las entidades tienen una antigüedad superior a diez años.

- La mayoría desarrollan su actividad únicamente en el País Vasco. 
- Por lo general, no desarrollan actividad mercantil.

- La asociación es la forma jurídica más habitual del sector y es la que cuenta con mayor participación de voluntariado.

- Las fundaciones poseen, en general, mayor presupuesto que las asociaciones.

- Los servicios sociales son la actividad con mayor peso específico y la más usual entre las asociaciones, mientras que la educación y la investigación lo son entre las fundaciones.

Además, a través de tablas de contingencias, comprobamos los siguientes aspectos:

- La fundación es la forma jurídica que en mayor medida desarrolla su actividad propia en el País
Vasco y en otras comunidades autónomas (Gráfico 1).

- Si medimos el peso específico que cada actividad propia tiene en el conjunto, observamos que los servicios sociales son la actividad más usual en estas entidades, seguida de la cultura y el ocio, y la educación y la investigación (Gráfico 2).

- Los servicios sociales son la actividad propia más usual entre las asociaciones, y la educación y la investigación lo son entre las fundaciones (Gráfico 3).

- La fundación es la forma jurídica con mayor porcentaje de entidades con presupuesto superior a 100.000 euros y con menor porcentaje de entidades con presupuesto menor o igual a 30.000 euros. En el caso de las asociaciones, sucede justo lo contrario (Gráfico 4).
Asociaciones

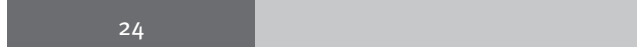

$\overline{\text { Fundaciones }}$

Fundaciones

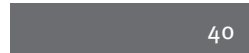

30

Otras del tercer sector

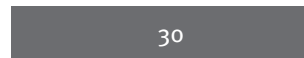

74

60

60

País Vasco y otras comunidades

Sólo País Vasco

NS/NC

Fuente: Maguregui (2014).

\section{Gráfico 2. Peso de cada actividad propia (\%)}

Cultura y ocio

Salud

Medio ambiente

Servicios legales, defensa y políticos

Actividades internacionales

Asociaciones profesionales, empresariales y sindicatos

Educación e investigación

Servicios sociales

Desarrollo y vivienda

Promoción del voluntariado e intermediarios

Actividades religiosas

No clasificados

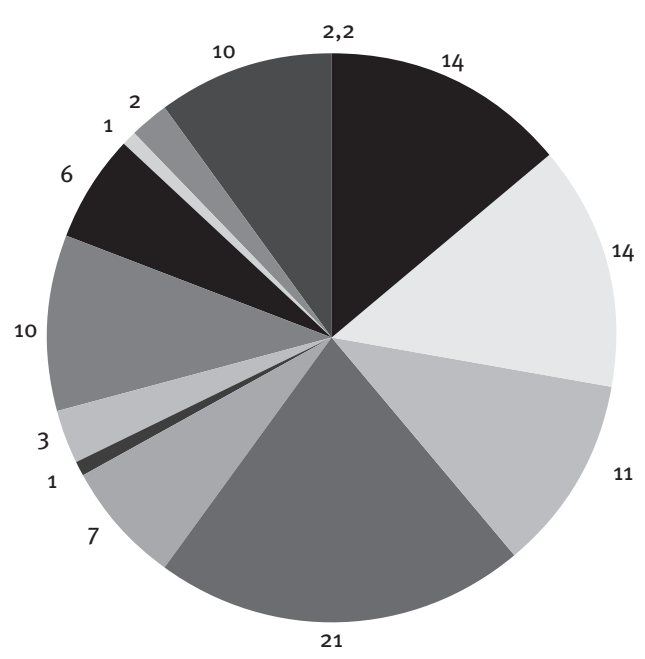

Fuente: Maguregui (2014). 
Gráfico 4. Presupuesto anual, según forma jurídica (\%)

Fundaciones

\section{6} 14 80

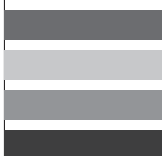

$\leq 30.000 €$

$30.001-100.000 €$

$>100.000 €$

NS/NC

Fuente: Maguregui (2014).

\subsection{Parámetros contables de las entidades}

Dada nuestra condición de contables, a partir de la entrada en vigor del Real Decreto 1491/2011, de 24 de octubre, por el que se Aprueban las Normas de Adaptación del Plan General de Contabilidad a las Entidades Sin Fines Lucrativos y el Modelo del Plan de Actuación de las Entidades Sin Fines Lucrativos, clasificamos las entidades encuestadas -siguiendo esa normativa y considerando que la dimensión temporal no es un elemento relevante para la investigación- en microentidades, pequeñas y medianas entidades, y macroentidades. Observamos que casi tres cuartas partes son microentidades y pequeñas y medianas entidades (Tabla 3). Como es lógico, casi la totalidad de las macroentidades y de las pequeñas y medianas entidades cuentan con un presupuesto superior a 100.000 euros, mientras que la inmensa mayoría de las asociaciones tiene un presupuesto inferior a dicha cuantía (Gráfico 6). 


\begin{tabular}{|c|c|c|c|}
\hline \multirow[t]{3}{*}{ Iotal activo } & \multirow[b]{2}{*}{$>2.850 .000 €$} & \multirow[b]{2}{*}{43} & \multirow[b]{2}{*}{22} \\
\hline & & & \\
\hline & $\mathrm{NS} / \mathrm{NC}$ & 17 & 9 \\
\hline \multirow{4}{*}{ Número de trabajadores empleados durante el ejercicio } & $\leq 5$ & 91 & 47 \\
\hline & 6-50 & 68 & 35 \\
\hline & $>50$ & 29 & 15 \\
\hline & NS/NC & 6 & 3 \\
\hline \multirow{4}{*}{ Volumen anual de ingresos } & $\leq 150.000 €$ & 72 & 37 \\
\hline & $150.001-5.700 .000 €$ & 95 & 49 \\
\hline & $>5.700 .000 €$ & 21 & 11 \\
\hline & NS/NC & 6 & 3 \\
\hline
\end{tabular}

NS/NC: no sabe o no contesta.

Fuente: Maguregui (2014).

Gráfico 5. Tipo de entidad, por tamaño (\%)

Macroentidades

Pequeñas y medianas entidades

Microentidades

$\mathrm{NS} / \mathrm{NC}$

Fuente: Maguregui (2014).

Gráfico 6. Presupuesto, según tamaño (\%)

\begin{tabular}{l} 
Microentidades \\
\hline
\end{tabular}

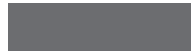

Pequeñas y medianas entidades

Macroentidades

$\leq 30.000 €$

30.001-100.000€

$>100.000 €$

Fuente: Maguregui (2014). 


\subsection{Parámetros de la gestión de la calidad y sus costes}

A partir de un estudio realizado por Maguregui (2014), en el que se analizan, entre otros muchos, los aspectos relativos a la gestión de la calidad total y sus costes en las entidades encuestadas, observamos que aspectos y variables que, a nuestro entender, son primordiales en este tipo de organizaciones resultan los que menor aceptación han tenido entre las entidades encuestadas: sólo el 21,2 \% de las entidades tienen departamento propio de calidad, y no son ni una quinta parte las que consideran que los informes sobre costes de calidad proporcionados por el departamento de contabilidad resultan fundamentales para la gestión de la calidad de la entidad y las que tienen el departamento de calidad relacionado con el de contabilidad (Tabla 4).
Resaltamos también que los objetivos y el código de conducta se han dado a conocer a todos los miembros de la entidad en mucha mayor proporción allí donde existe una política de calidad formalizada, por escrito (Tabla 7).

A la vista del Gráfico 8, podemos concluir que resulta primordial que los departamentos de calidad y contabilidad estén relacionados para que los informes de costes de calidad resulten fundamentales en la gestión de la calidad de la entidad.

\subsection{Medición de los costes de calidad}

Del citado estudio (Maguregui, 2014), se desprende que las entidades no lucrativas del País Vasco, en general, no miden los distintos costes de calidad

Tabla 4. Aspectos fundamentales de la gestión de la calidad total y sus costes, por tamaño de entidad (\%)

\begin{tabular}{|c|c|c|c|c|}
\hline & \\
\hline & Microentidades & $\begin{array}{l}\text { Pequeñas } \\
\text { y medianas } \\
\text { entidades }\end{array}$ & Macroentidades & Media \\
\hline Existe una política de calidad formalizada, por escrito & 25,0 & 47,7 & 92,3 & 46,1 \\
\hline $\begin{array}{l}\text { Los objetivos y el código de conducta de la entidad se han dado a conocer a } \\
\text { todos los miembros de ésta }\end{array}$ & 71,9 & 77,3 & 92,3 & 77,5 \\
\hline La entidad tiene departamento propio de calidad & 6,7 & 21,4 & 53,8 & 21,2 \\
\hline El departamento de calidad está relacionado con el de contabilidad & 10,0 & 23,8 & 15,4 & 17,6 \\
\hline $\begin{array}{l}\text { Los informes sobre costes de calidad proporcionados por el departamento de } \\
\text { contabilidad resultan fundamentales para la gestión de la calidad }\end{array}$ & 13,8 & 21,4 & 23,1 & 19,0 \\
\hline
\end{tabular}

Fuente: Maguregui (2014).

Gráfico 7. Relación entre la existencia de una política de calidad formalizada (por escrito), y la difusión de los objetivos y el código de conducta entre los miembros de la entidad (\%)

\begin{tabular}{|l|l|}
\hline $\begin{array}{c}\text { Sí existe una política } \\
\text { de calidad formalizada }\end{array}$ & 93 \\
\hline $\begin{array}{l}\text { No existe una política } \\
\text { de calidad formalizada }\end{array}$ & 67 \\
\hline $\begin{array}{l}\text { Sí se han dado a conocer } \\
\text { No se han dado a conocer } \\
\text { NS/NC }\end{array}$ \\
\hline
\end{tabular}

Fuente: Maguregui (2014).

Gráfico 8. Importancia concedida a los informes de costes de calidad, según la relación existente entre los departamentos de calidad y contabilidad

Existe relación entre los departamentos de calidad y contabilidad

No existe relación entre los departamentos de calidad y contabilidad

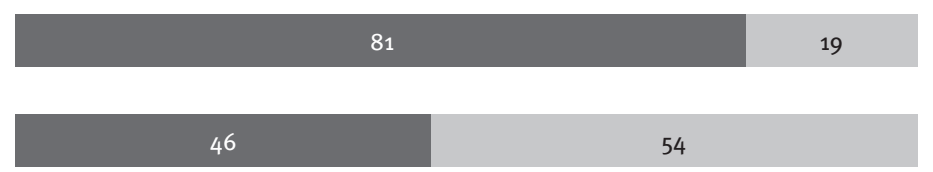

Los informes de costes de calidad se consideran fundamentales

Los informes de costes de calidad no se consideran fundamentales

Fuente: Maguregui (2014). 
Tabla 5. Medición de los costes de calidad, según tamaño de la entidad (\%)

\begin{tabular}{|l|c|c|c|c|}
\cline { 2 - 5 } \multicolumn{1}{c|}{} & Microentidades & $\begin{array}{c}\text { Pequeñas } \\
\text { y medianas } \\
\text { entidades }\end{array}$ & Macroentidades & Media \\
\hline Costes de prevención & 17,2 & 41,9 & 61,5 & 36,5 \\
\hline Costes de evaluación & 20,7 & 30,2 & 46,2 & 29,4 \\
\hline Costes de fallos internos & 20,7 & 25,6 & 23,1 & 23,5 \\
\hline Costes de fallos externos & 17,2 & 23,2 & 15,4 & 19,8 \\
\hline Costes intangibles & 13,6 & 23,1 & 30,4 & 19,9 \\
\hline Costes de oportunidad & 17,2 & 18,6 & 15,4 & 17,6 \\
\hline
\end{tabular}

Fuente: Maguregui (2014).

(Tabla 5): sólo lo hacen el $24,4 \%$ de las entidades encuestadas. Los costes que más se miden son los de prevención, los de evaluación y los de fallos internos. Los costes de fallos externos, los intangibles y los de oportunidad no son medidos ni por una quinta parte de las entidades. Este resultado nos parece el más significativo, a la vez que alarmante. Es un aspecto que nos preocupa y que debemos intentar modificar.

\subsection{Conocimiento y aplicación de las herramientas específicas de gestión de la calidad aplicables a las entidades no lucrativas, y principales beneficios e inconvenientes derivados de su implantación}

En cuanto a las herramientas de gestión de la calidad aplicables en las entidades no lucrativas, el estudio especifica que el conocimiento medio que las entidades tienen de ellas es del $16,8 \%$, y su aplicación media, del 7,3\% (Tabla 6). Consideramos que son unos porcentajes muy bajos, y es también realmente preocupante que la mayoría de estas entidades sigan sin conocer las herramientas de gestión de la calidad específicas para ellas.

El EFQM es, junto con los códigos de conducta, la herramienta que más conocen y aplican. Casi la mitad de las macroentidades aplican el EFQM para el Sector Público y las Organizaciones del Voluntariado. Interesa también destacar que el modelo EFQM de excelencia para el sector público y las organizaciones del voluntariado es la herramienta de este grupo más aplicada por las macroentidades. Los códigos de conducta y las guías de la transparencia y de las buenas prácticas son, por su parte, las que más aplican las microentidades y las pequeñas y medianas entidades. La norma ONG con Calidad y el procedimiento de calificación de organización no gubernamental para el desarrollo (ONGD) de la Agencia Española de Cooperación Internacional (AECI) no las aplica ninguna macroentidad. Constatamos, además, que ninguna de las entidades encuestadas aplica la norma UNE 165011:2005 de Aenor.

Tabla 6. Conocimiento y uso de las herramientas de gestión de la calidad aplicables en las entidades no lucrativas, según tamaño de la entidad (\%)

\begin{tabular}{|c|c|c|c|c|c|c|c|c|}
\hline & \multicolumn{2}{|c|}{ Microentidades } & \multicolumn{2}{|c|}{$\begin{array}{c}\text { Pequeñas y medianas } \\
\text { entidades }\end{array}$} & \multicolumn{2}{|c|}{ Macroentidades } & \multicolumn{2}{|c|}{ Media } \\
\hline & Conoce & Aplica & Conoce & Aplica & Conoce & Aplica & Conoce & Aplica \\
\hline $\begin{array}{l}\text { Norma UNE 165011:2005 EX. “Ética. } \\
\text { Sistema de gestión de las ONG" (Aenor) }\end{array}$ & 7,5 & 0,0 & 13,1 & 0,0 & 17,6 & 0,0 & 11,0 & 0,0 \\
\hline Normas ISO 9000 & 11,3 & 1,9 & 23,0 & 9,8 & 41,2 & 23,5 & 20,5 & 9,2 \\
\hline $\begin{array}{l}\text { Modelo EFQM de excelencia para el } \\
\text { sector público y organizaciones del } \\
\text { voluntariado }\end{array}$ & 11,3 & 0,0 & 29,5 & 11,5 & 58,8 & 47,1 & 23,9 & 10,3 \\
\hline Norma ONG Con Calidad & 5,7 & 1,9 & 13,1 & 1,6 & 5,9 & 0,0 & 9,0 & 1,3 \\
\hline $\begin{array}{l}\text { Procedimiento de calificación de ONGD } \\
\text { de } \mathrm{AECl}\end{array}$ & 5,7 & 1,9 & 14,8 & 4,9 & 5,9 & 0,0 & 9,7 & 3,1 \\
\hline Códigos de conducta & 17,0 & 7,5 & 24,6 & 23,0 & 29,4 & 17,6 & 22,6 & 15,5 \\
\hline $\begin{array}{l}\text { Guía de la transparencia y de las buenas } \\
\text { prácticas de las ONG }\end{array}$ & 18,9 & 3,8 & 24,6 & 19,7 & 29,4 & 11,8 & 21,3 & 11,6 \\
\hline
\end{tabular}

ONGD: organización no gubernamental para el desarrollo. AECI: Agencia Española de Cooperación Internacional. Fuente: Maguregui (2014). 
Comparando el conocimiento y la aplicación de las distintas herramientas (Gráfico 9), comprobamos que los códigos de conducta son los que mayor éxito tienen, mientras que la norma ONG Con Calidad es la que menos.
En lo que al estado del sistema de gestión de la calidad se refiere, se pidió a las entidades encuestadas que señalaran la opción respondía a su situación (Gráfico 10). Como era de esperar tras conocer las respuestas obtenidas en los apartados anteriores, 'no estamos certificados’ es la opción más elegida (58\%).

\section{Gráfico 9. Éxito de las herramientas de gestión de la calidad aplicables en las entidades no lucrativas (\%)}

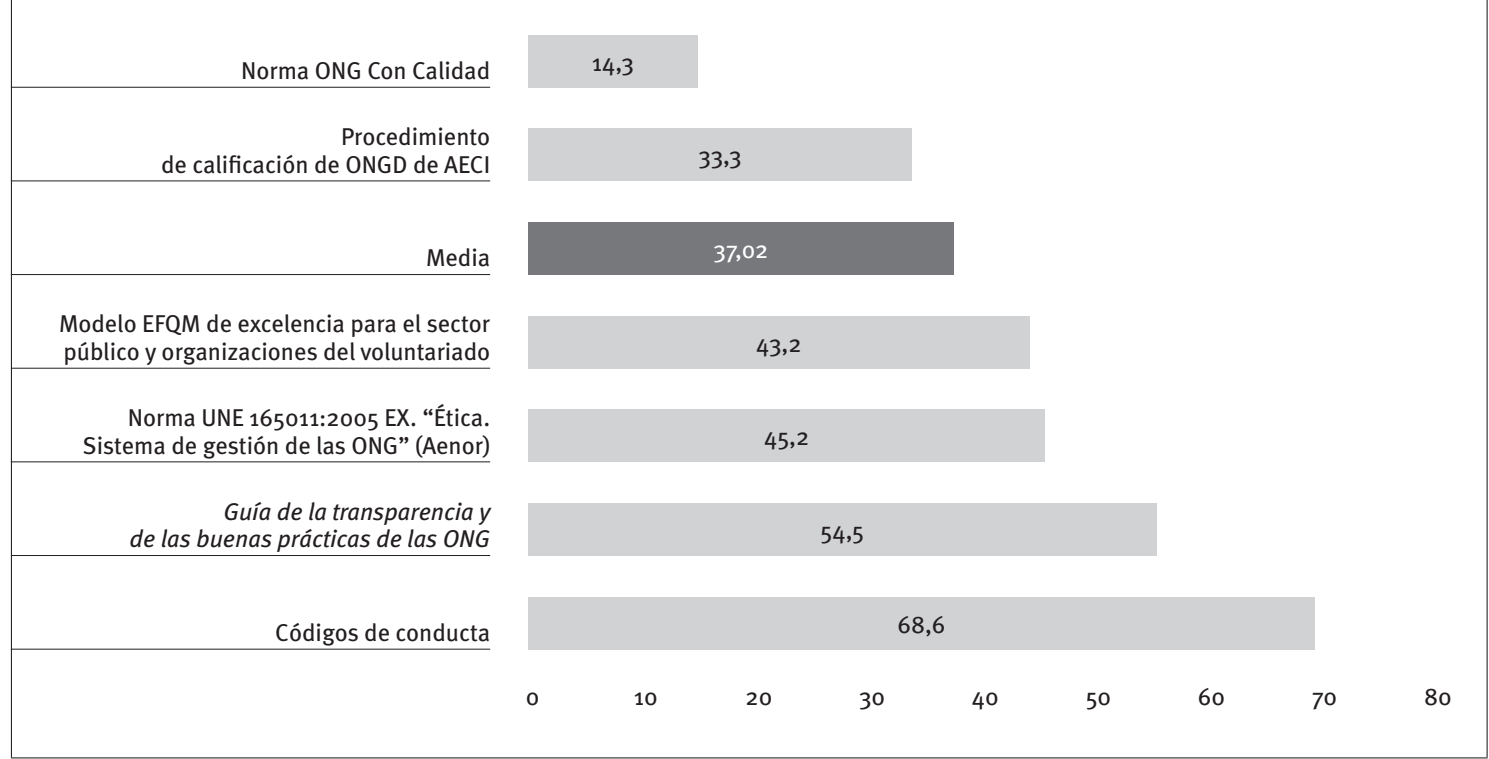

Fuente: Maguregui (2014).

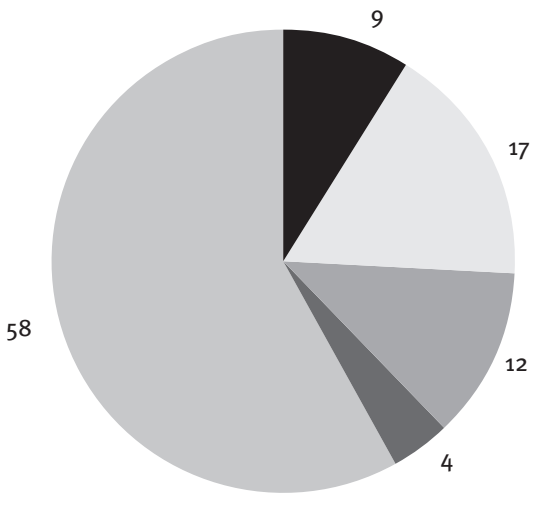

Estamos certificados en ISO 9000-2012 o alguna de sus variantes

Hemos iniciado el proceso de implantación de la norma

No estamos certificados

Fuente: Maguregui (2014). 
Si lo analizamos en función del tamaño de la entidad (Gráfico 11), observamos que el $94 \%$ de las microentidades eligen la opción 'no estamos certificados'. Por su parte, el $26 \%$ de las macroentidades señalan tener el certificado ISO 9000, y el 35\%, autoevaluarse con el modelo EFQM para el sector público y las organizaciones del voluntariado.

De los beneficios que puede reportar la implantación de herramientas de gestión de la calidad (Gráfico 12), los dos que las entidades encuestadas consideran más importantes son mejorar la eficacia y la eficiencia de la gestión (31\%), y mejorar la imagen (26\%). Por su parte, incrementar voluntarios, socios, donantes y financiadores no son apenas identificados como beneficios de la implantación de herramientas de gestión de la calidad.

Se pidió a las entidades encuestadas que señalaran, mediante respuesta múltiple, los tres beneficios que consideraban más importantes ${ }^{1}$ (Gráfico 13 ).
Mejorar la eficacia y la eficiencia de la gestión son los más señalados por todas las entidades encuestadas, independientemente de su tamaño, aunque le sigue de cerca el de mejorar la imagen. La tercera ventaja más señalada es, por su parte, incrementar la confianza de los usuarios.

El elevado consumo de recursos humanos es considerado el principal inconveniente o limitación para implantar las herramientas de gestión de la calidad (Gráfico 14), aunque también les preocupa el elevado consumo de recursos materiales, la resistencia al cambio y el desconocimiento de los sistemas y herramientas de gestión de la calidad.

Si lo analizamos en función del tamaño de las entidades (Gráfico 15), la resistencia al cambio es, junto con el consumo de recursos humanos, la limitación más importante en las macroentidades, mientras que el desconocimiento de los sistemas y herramientas de la gestión de la calidad adquiere la misma

Gráfico 11. Estado del sistema de gestión de la calidad, según tamaño de la entidad (\%)

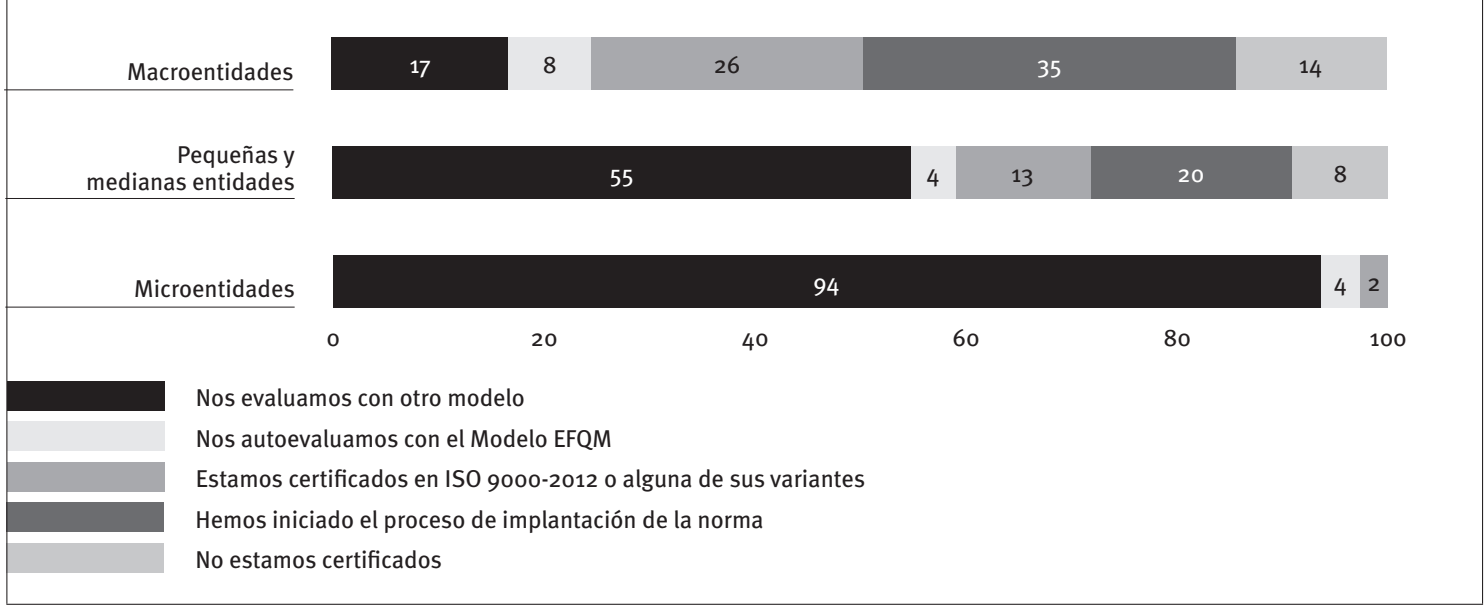

Fuente: Maguregui (2014).

Gráfico 12. Peso específico de los beneficios de la implantación de herramientas de gestión de la calidad (\%)

Mejorar la imagen

Mejorar la eficacia y la eficiencia de la gestión

Requisito para obtener financiación

Incrementar la confianza de los usuarios

Incrementar donantes y financiadores

Incrementar socios

Incrementar voluntarios

Otro

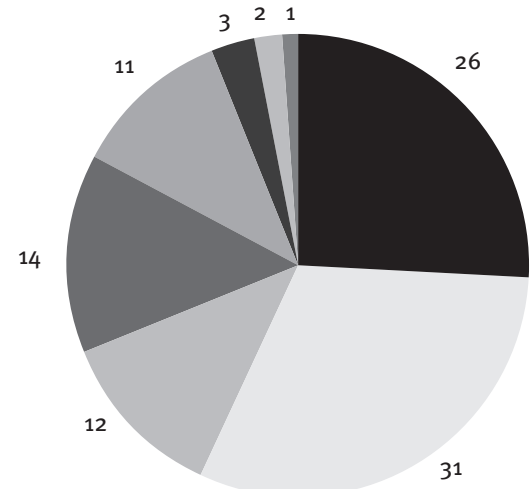

Fuente: Maguregui (2014).

${ }^{1}$ El total excede, por tanto, del $100 \%$. 
Gráfico 13. Beneficios más importantes de la implantación de herramientas de gestión de la calidad, según tamaño de la entidad (\%)

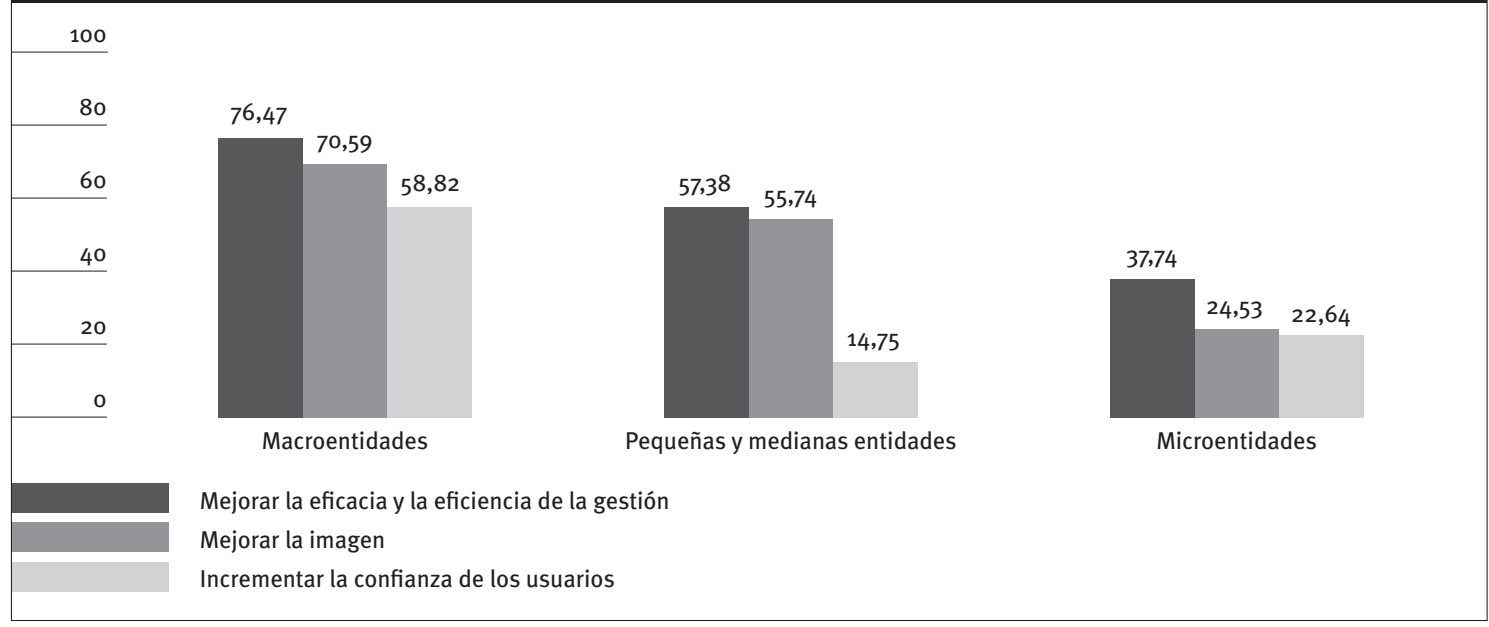

Fuente: Maguregui (2014).

\section{Gráfico 14. Peso específico de las limitaciones para implantar herramientas de gestión de la calidad (\%)}

Elevado consumo de recursos humanos Elevado consumo de recursos materiales Resistencia al cambio

Demasiado esfuerzo para los resultados que puedan obtenerse Desconocimiento de los sistemas y herramientas de gestión de la calidad No se considera necesario ningún sistema de gestión de la calidad

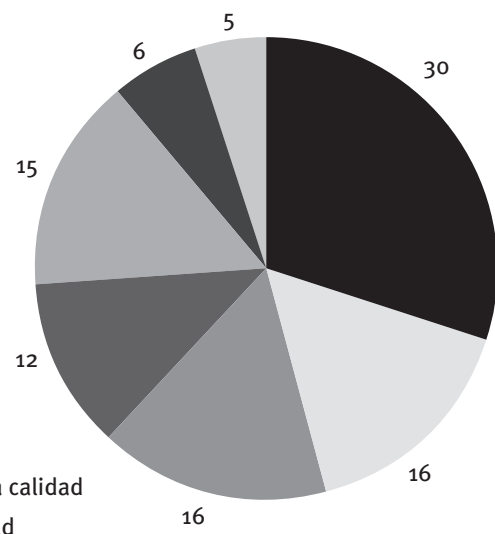
Otro

Fuente: Maguregui (2014).

Gráfico 15. Limitaciones más importantes para implantar herramientas de gestión de la calidad, según tamaño de la entidad (\%)

\begin{tabular}{|r|}
\hline 70 \\
\hline 60 \\
\hline 50 \\
\hline 40 \\
\hline 30 \\
\hline 20 \\
\hline 10 \\
\hline 0 \\
\hline
\end{tabular}

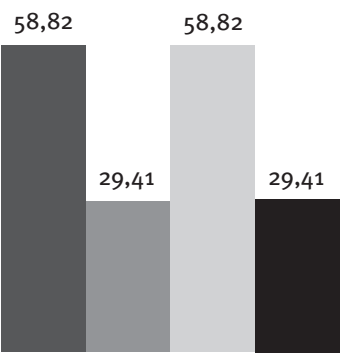

Macroentidades

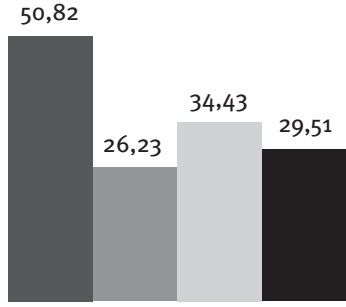

Pequeñas y medianas entidades

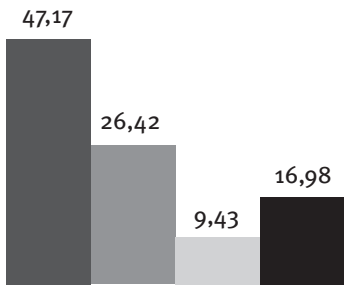

Microentidades

Elevado consumo de recursos humanos

Elevado consumo de recursos materiales Resistencia al cambio

Desconocimiento de los sistemas y herramientas de gestión de la calidad 
importancia que el elevado consumo de recursos materiales. En las microentidades, sin embargo, el elevado consumo de recursos humanos y materiales, junto con el desconocimiento de los sistemas y herramientas de gestión de la calidad son limitaciones que preocupan a más entidades que la resistencia al cambio ${ }^{2}$.

\subsection{Conocimiento y aplicación de los modelos de medición de costes totales de calidad}

Respecto a los modelos de medición de costes totales de calidad, y recordando los porcentajes tan bajos obtenidos en la medición de los costes de calidad, es lógico que en el citado estudio (Maguregui, 2014) se compruebe que el conocimiento medio $(9,4 \%)$ y la aplicación media $(5,7 \%)$ de dichos modelos sean realmente bajos (Tabla 7). Este aspecto, como hemos señalado anteriormente, nos preocupa mucho.

Asimismo, resulta interesante comprobar que las entidades que cuentan con un presupuesto menor 0 igual a 30.000 euros son las que, teniendo un menor conocimiento de los modelos de costes totales de la calidad, hacen una mayor aplicación de ellos: mientras que el grado medio de aplicación de estas

Tabla 7. Conocimiento y aplicación de los modelos de medición de costes totales de calidad, según tamaño de la entidad (\%)

\begin{tabular}{|l|c|c|c|c|c|c|c|c|}
\cline { 2 - 11 } \multicolumn{1}{c|}{} & \multicolumn{2}{c|}{ Microentidades } & \multicolumn{2}{c|}{$\begin{array}{c}\text { Pequeñas y medianas } \\
\text { entidades }\end{array}$} & \multicolumn{2}{c|}{ Macroentidades } & \multicolumn{4}{c|}{ Media } \\
\cline { 2 - 12 } \multicolumn{1}{c|}{} & Conoce & Aplica & Conoce & Aplica & Conoce & Aplica & Conoce & Aplica \\
\hline Prevención y evaluación & 5,7 & 3,8 & 13,1 & 8,2 & 17,6 & 5,9 & 9,0 & 5,2 \\
\hline Coste-beneficio & 3,8 & 1,9 & 16,4 & 11,5 & 17,6 & 11,8 & 11,0 & 7,7 \\
\hline Costes por procesos & 3,8 & 3,8 & 19,7 & 8,2 & 29,4 & 23,5 & 12,3 & 7,7 \\
\hline Costes de fallos internos y externos & 1,9 & 1,9 & 13,1 & 3,3 & 11,8 & 11,8 & 7,1 & 3,2 \\
\hline Costes ocultos & 1,9 & 1,9 & 11,5 & 0,0 & 5,9 & 5,9 & 5,8 & 1,3 \\
\hline Just No Defect & 1,9 & 1,9 & 9,8 & 0,0 & 5,9 & 0,0 & 4,5 & 0,6 \\
\hline ABC & 5,7 & 1,9 & 13,1 & 4,9 & 5,9 & 0,0 & 7,7 & 2,6 \\
\hline Medidas financieras y no financieras & 3,8 & 3,8 & 13,1 & 13,1 & 29,4 & 23,5 & 11,0 & 9,7 \\
\hline Gestión de la calidad total & 3,8 & 3,8 & 24,6 & 16,4 & 35,3 & 35,3 & 16,1 & 12,9 \\
\hline
\end{tabular}

Fuente: Maguregui (2014).

Gráfico 16. Conocimiento y aplicación de los modelos de medición de costes totales de calidad en las entidades con presupuesto anual inferior a 30.000 euros (\%)

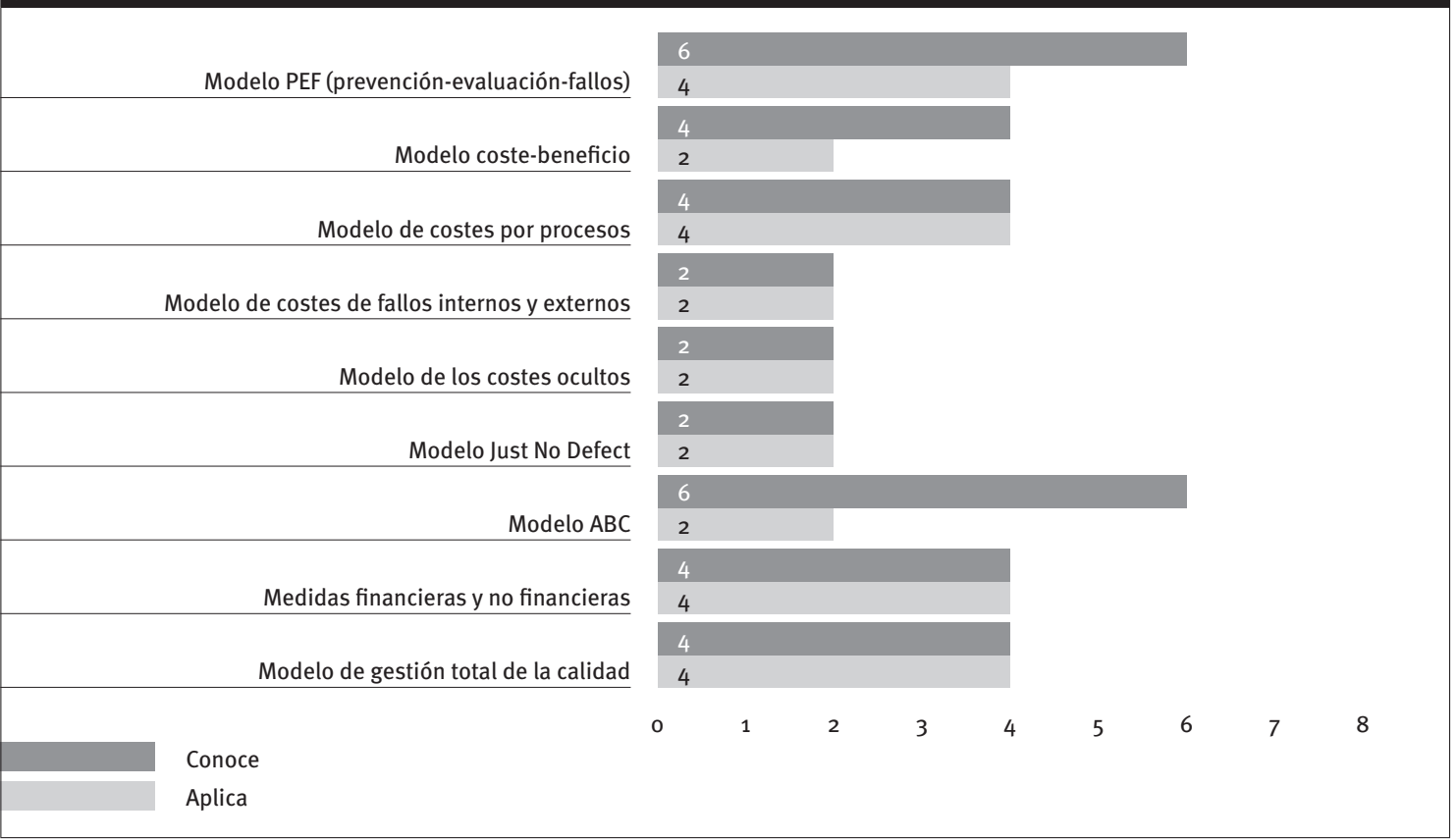

Fuente: Maguregui (2014).

${ }^{2}$ Al igual que ocurría con los beneficios, se trata de una pregunta de respuesta múltiple, por lo que el total excede del $100 \%$. 
herramientas es tan sólo del $16 \%$ en las de presupuesto superior a 100.000 euros y del $22 \%$ en las de presupuesto de entre 30.001 y 100.000 euros, en las de menos de 30.000 euros ese porcentaje es del $29 \%$, notablemente superior. Así, el grado de éxito de los modelos de este grupo es elevadísimo en las entidades con presupuesto anual inferior a 30.000 euros (Gráfico 16). Parece lógico: las entidades con menos recursos son las que realizan una aplicación más eficiente.

Por otro lado, comprobamos que las medidas financieras y no financieras son el modelo que mayor éxito tiene (Gráfico 17).
En cuanto a las herramientas de medición y control de la calidad, el grado de conocimiento medio es del 18,1\%, y el de aplicación, del 12,3\% (Tabla 8). Las más conocidas son las encuestas o cuestionarios, conocidas y aplicadas por el 32,8\% de las entidades encuestadas. Le siguen muy de cerca las quejas y sugerencias, que son conocidas por un $31,6 \%$ y aplicadas por el $\mathbf{2 9 , 7} \%$. Por el contrario, la función de pérdida de Taguchi y los estudios de precisión son las herramientas de este grupo que menos se conocen y aplican: concretamente, la función de pérdida de Taguchi no es aplicada por ninguna entidad pequeña o mediana, ni por ninguna macroentidad, y sólo por un $1,9 \%$ de las microentidades.

Gráfico 17. Éxito de los modelos de medición de costes totales de calidad (\%)

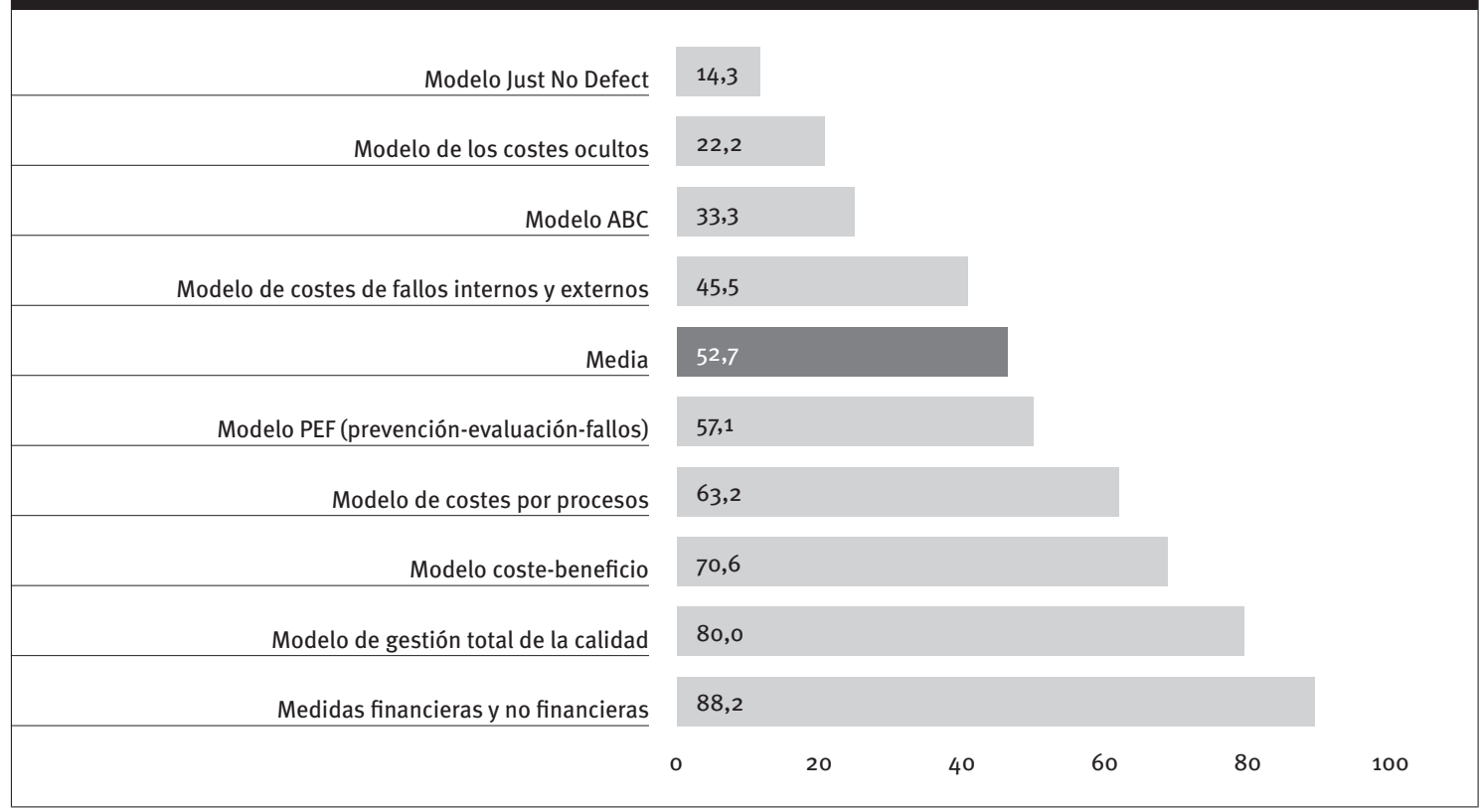

Fuente: Maguregui (2014).

Tabla 8. Conocimiento y aplicación de las herramientas de medición y control de la calidad, según tamaño de la entidad (\%)

\begin{tabular}{|l|c|c|c|c|c|c|c|c|}
\cline { 2 - 10 } \multicolumn{2}{c|}{} & \multicolumn{2}{c|}{ Microentidades } & \multicolumn{2}{c|}{$\begin{array}{c}\text { Pequeñas y medianas } \\
\text { entidades }\end{array}$} & \multicolumn{2}{c|}{ Macroentidades } & \multicolumn{4}{c|}{ Media } \\
\cline { 2 - 10 } & Conoce & Aplica & Conoce & Aplica & Conoce & Aplica & Conoce & Aplica \\
\hline Diagrama de Pareto & 5,7 & 1,9 & 26,2 & 3,3 & 47,1 & 23,5 & 19,4 & 4,5 \\
\hline Gráficos de control & 7,5 & 3,8 & 31,1 & 14,8 & 52,9 & 41,2 & 23,2 & 12,9 \\
\hline Hojas de recogida de datos & 11,3 & 7,5 & 32,8 & 32,8 & 58,8 & 58,8 & 25,3 & 23,9 \\
\hline Histograma & 7,5 & 5,7 & 19,7 & 8,2 & 41,2 & 23,5 & 16,8 & 9,0 \\
\hline Diagrama de correlación & 3,8 & 1,9 & 9,8 & 4,9 & 17,6 & 5,9 & 8,4 & 3,2 \\
\hline Función de pérdida de Taguchi & 1,9 & 1,9 & 6,6 & 0,0 & 23,5 & 0,0 & 5,8 & 0,6 \\
\hline Hojas de registro de tiempos & 9,4 & 7,5 & 23,0 & 14,8 & 29,4 & 29,4 & 17,4 & 12,3 \\
\hline Estudios de precisión & 3,8 & 3,8 & 8,2 & 1,6 & 17,6 & 5,9 & 7,7 & 2,6 \\
\hline Encuesta o cuestionario & 13,2 & 13,2 & 41 & 41 & 64,7 & 64,7 & 32,8 & 32,8 \\
\hline Quejas y sugerencias & 15,1 & 11,3 & 39,3 & 39,3 & 70,6 & 70,6 & 31,6 & 29,7 \\
\hline Análisis de tendencias & 7,5 & 5,7 & 18,0 & 9,8 & 35,3 & 29,4 & 14,8 & 10,3 \\
\hline Evaluación 360 & 1,9 & 1,9 & 19,7 & 3,3 & 35,3 & 35,3 & 14,2 & 6,5 \\
\hline
\end{tabular}

Fuente: Maguregui (2014). 


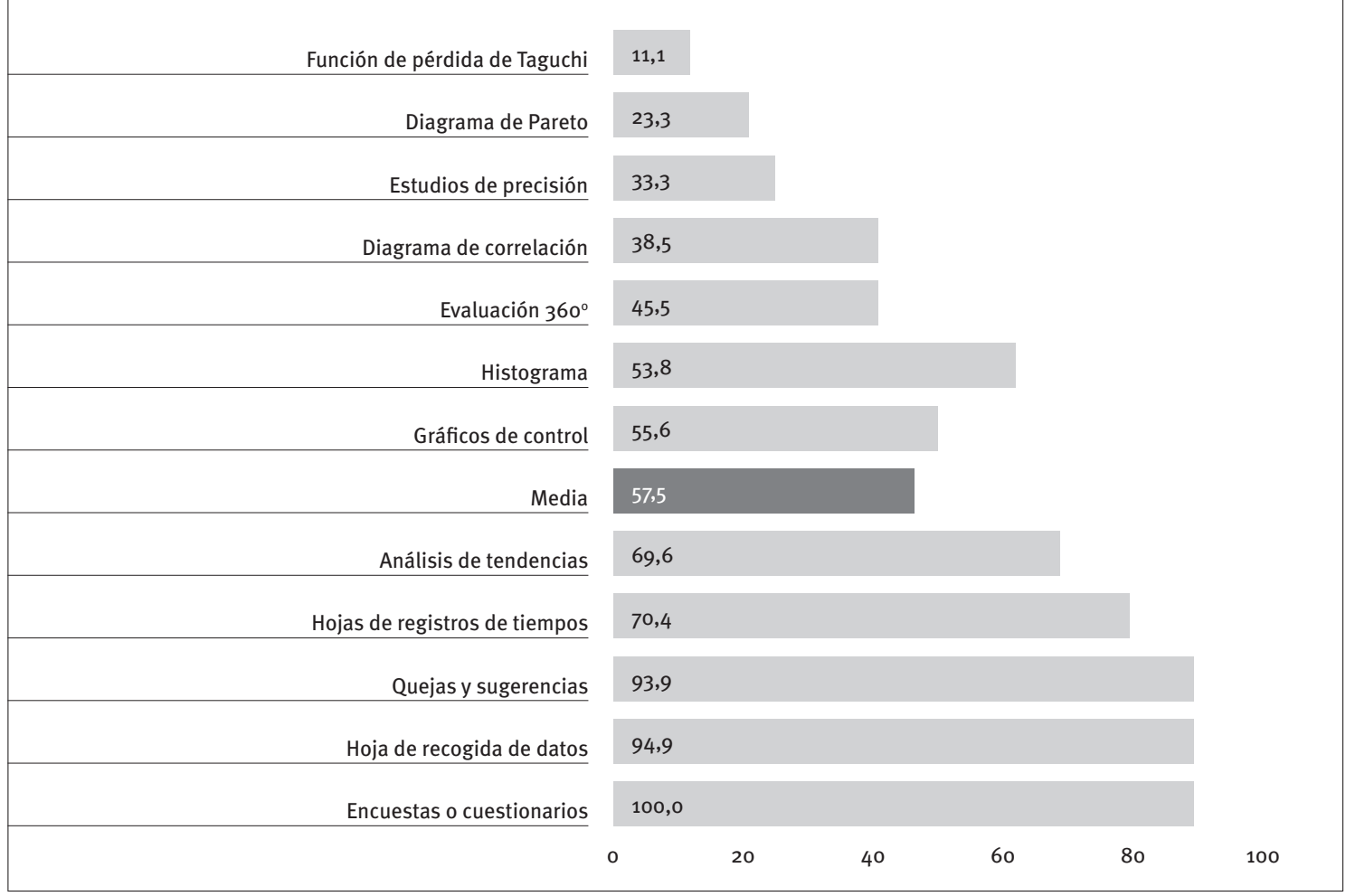

Fuente: Maguregui (2014).

Como era de esperar, las encuestas o cuestionarios tienen un grado de éxito del $100 \%$, seguidos de la hoja de recogida de datos, y las quejas y sugerencias (Gráfico 18).

\section{Conclusiones}

- A pesar de que las entidades no lucrativas del País Vasco conforman un sector social maduro, con mucha tradición y experiencia, tienen pendiente un aspecto primordial: la medición de los costes de calidad de sus actividades, puesto que no disponen de un sistema depurado para ello.

- El comportamiento activo de las entidades no lucrativas ante los costes que desarrollan y la reducción de éstos ha de incorporarse a la cultura organizativa de organización. En este cambio, las claves más importantes son, por una parte, la gestión y control de costes, y por otra, la gestión de la calidad.

- Las entidades no lucrativas precisan desarrollar el sistema de costes de calidad que mejor se adecue a las particularidades de la organización y de todos sus miembros, siendo imprescindible la colaboración entre el departamento de contabilidad y el de calidad, que han de cooperar con todas las demás áreas y contar con el compromiso del personal de la alta dirección.

- La creación y defensa de valores sociales y éticos en las entidades no lucrativas pueden y deben ir acompañadas de una gestión de calidad, y ésta, a su vez, de la necesidad de conocer y aplicar instrumentos y soportes adecuados, que ayudan, pero no son garantía absoluta de que la entidad crezca y trabaje con calidad.

- Es necesario que la gestión de la calidad esté totalmente integrada en el propio tejido de la organización y que las herramientas de gestión de la calidad no sean consideradas como simple prerrequisito para acceder a ciertas fuentes de financiación, sino con el objetivo de lograr, efectivamente, la mejora de la eficacia y la eficiencia de su gestión. Existe un interés creciente por la calidad en las entidades no lucrativas privadas del País Vasco, pero el panorama es aún algo confuso.

- En aras a alcanzar el equilibrio entre la dimensión económica y la dimensión social, resulta imprescindible que las entidades no lucrativas creen y apliquen herramientas de gestión adecuadas. Sus presupuestos se han visto fuertemente reducidos como consecuencia de la actual crisis financiera, y esto puede tener consecuencias negativas en sus resultados, es decir, en la calidad de los servicios sociales que prestan.

- Resulta imprescindible desarrollar el área de formación de las entidades no lucrativas y que cuenten con unas guías específicas que les ayuden a mejorar el nivel de conocimiento y, en consecuencia, de aplicación de los distintos instrumentos y herramientas. 
ÁLVAREZ DE MON, S. (1998): El tercer sector: retos y propuestas para el próximo milenio, Madrid, Ministerio de Trabajo y Asuntos Sociales.

ASOCIACIÓN ESPAÑOLA DE CONTABILIDAD Y ADMINISTRACIÓN DE EMPRESAS (2002): La contabilidad de gestión en las entidades sin fines de lucro, serie Principios de Contabilidad de Gestión, no-24, Madrid, Asociación Española de Contabilidad y Administración de Empresas.

- (1994): Estudio sobre la implantación de la contabilidad de gestión en España, Madrid, Asociación Española de Contabilidad y Administración de Empresas.

CONFEDERACIÓN EMPRESARIAL ESPAÑOLA DE ECONOMÍA SOCIAL (2011): El impacto socioeconómico de las entidades de economía social, Madrid, Confederación Empresarial Española de Economía Social.

EISENHARDT, K. M. (1989): "Building theories from case studies research", The Academy of Management Review, vol. 14, no 4, págs. 532-550.

ESPAÑA (2011): "Real Decreto 1491/2011, de 24 de octubre, por el que se Aprueban las Normas de Adaptación del Plan General de Contabilidad a las Entidades Sin Fines Lucrativos y el Modelo de Plan de Actuación de las Entidades Sin Fines Lucrativos", Boletín Oficial del Estado, nํ283, 24-12-11, págs. 124.263124.398 [ [http://www.boe.es/buscar/doc. php?id=BOE-A-2011-18458>].

FUNDACIÓN EDE (2008): Proyecto de investigación-acción sobre la gestión de la calidad en el tercer sector de acción social de Bizkaia (2005-2008), Bilbao, Fundación EDE; BBK Obra Social.

FUNDACIÓN PRICEWATERHOUSECOOPERS (2014): La reacción del tercer sector social al entorno de crisis, Fundación La Caixa; Instituto de Innovación Social de ESADE; Fundación PricewaterhouseCoopers.

- (2013): Estudio sobre el presente y futuro del Tercer Sector Social en un entorno de crisis, Fundación La Caixa; Instituto de Innovación Social de ESADE; Fundación PricewaterhouseCoopers.

GARCÍA DELGADO, J. L. (dir.) (2009): Las cuentas de la economía social. Magnitudes y financiación del tercer sector en España, 2005, Madrid, Thomson-Civitas; Fundación ONCE; Confederación Empresarial Española de la Economía Social.

GOBIERNO VASCO (2011): II Plan Vasco de Voluntariado. Prórroga 2011-2012, Vitoria-Gasteiz, Eusko Jaurlaritza-Gobierno Vasco [rhttp://www. gizartelan.ejgv.euskadi.net/r45-contpfc/es/ contenidos/informacion/plan_vasco_de_ voluntariado/es_voluntar/adjuntos/Prórroga II Plan Vasco Voluntariado, 2011-2012.pdf $>$ ].

INSTITUTO DE CONTABILIDAD Y AUDITORÍA DE CUENTAS (1998): Boletín del Instituto de Contabilidad y Auditoría de Cuentas, nํㅜ 34, anexo I, punto II.15.

MAGUREGUI, M. L. (2014): El reto de la gestión de la calidad y sus costes en las entidades no lucrativas: modelo y aplicación al País Vasco, Bilbao, Servicio Editorial de la Universidad del País Vasco.

MARTÍNEZ CHURIAQUE, J. I. (2003): “Ante la necesaria espera para contrastar el avance del pensamiento contable producido por la investigación empírica", Revista Española de Financiación y Contabilidad, vol. 32, nㅜ 119, págs. 1.205-1.219.

MATAIX, C. (2001): Dirección estratégica para las ONG, Madrid, Uned. 
MILES, M. B.; y HUBERMAN, A.M. (1994): Qualitative Data Analysis: An Expanded Sourcebook, Thousand Oaks, Sage.

MONTSERRAT CODORNIU, J.; y RODRÍGUEZ CABRERO, G. (1996): "Dimensión económica del sector de las entidades no lucrativas en servicios sociales", en MONTSERRAT CODORNIU, J.; y RODRÍGUEZ CABRERO, G. (coord.), Las entidades voluntarias en España: institucionalización, estructura económica y desarrollo asociativo, Madrid, Ministerio de Asuntos Sociales.

MONZÓN CAMPOS, J. L. (dir.) (2010): Las grandes cifras de la economía social en España. Ámbito, entidades y cifras clave. Año 2008, Valencia, CiriecEspaña.

ORTEGA MARTÍNEZ, E. (1994): Manual de investigación comercial, Madrid, Pirámide.

PAÍS VASCO (2013): “Decreto 424/2013, de 7 de octubre, sobre la Declaración de Interés Social de las Entidades Sin Ánimo de Lucro de Servicios Sociales", Boletín Oficial del País Vasco, n200, 18-10-13 [<https://www.euskadi.eus/r47bopvapps/es/bopv2/datos/2013/10/1304439a. shtml>].

- (1994): "Ley 12/1994, de 17 de junio, de Fundaciones", Boletín Oficial del País Vasco, no-135, 15-7-1994 [khttps://www.euskadi.eus/r47-bopvvaci/es/ bopv2/datos/1994/07/9402550a.shtml/].

RIPOLL, V. (2012): "Si una empresa no implementa un sistema de control de gestión, está condenada al fracaso" [entrevista], .edu, 16-4-12 [<http://puntoedu.pucp.edu.pe/entrevistas/ contabilidad-de-gestion/>].

- (coord.) (1996): Contabilidad de gestión avanzada. Planificación, control y experiencias prácticas, Madrid, McGraw Hill; Madrid, Asociación Española de Contabilidad y Administración de Empresas.
ROVIRA, M. R.; JEREZ, F.; y JOHANISOVA, N. (2012): "Transparencia y rendición de cuentas en las entidades no lucrativas. El caso de las fundaciones", Revista de Contabilidad y Dirección, n-14, págs. 159-181.

RUIZ OLABUÉNAGA, J. I. (2012): Metodología de la investigación cualitativa, Bilbao, Universidad de Deusto.

- (dir.) (2006): El sector no lucrativo en España: una visión reciente, Bilbao, Fundación BBVA.

SENOVILLA, M. (2013): "La importancia del control de costes en la empresa", Cámara Oficial de Comercio, Industria y Servicios de Zaragoza, 23-2-12 [rhttp://www.camarazaragoza.com/actualidad/ la-importancia-del-control-de-costes-en-laempresa/s].

SOCÍAS, A. et al. (2013): Contabilidad de entidades sin fines lucrativos. Nociones básicas, el PGC de 2011 y análisis contable, Madrid, Pirámide.

UNERMAN, J.; y O’DWYER, B. (2010): “NGO accountability and sustainability issues in the changing global environment", Public Management Review, vol. 12, nํㅜ 4, págs. 475-486.

VASSALLO, J. M. (2012): “Control de costes: la respuesta a la crisis", VidaEconómica.com, 17-9-12 [‘http:// www.vidaeconomica.com/control-de-costes-larespuesta-a-la-crisis_t1174.htm〉].

VIDAL, P. (2013a): “5 temas clave donde el tercer sector se la juega en 2013", TercerSector.net, 9-1-13 [rhttp://www.tercersector.net/wp-trackback. php? $\mathrm{p}=882$ \&lang=es $>$.

- (2013b): "La reconversión (milagrosa) del tercer sector: sin recursos y con valores", TercerSector. net, 24-1-13 [shttp://www.tercersector. net $/ \mathrm{p}=895$ \&lang=es $)$.

YIN, R. (1994): Case Study Research. Design and Methods, Londres, Sage. 